Even though the methodologies to measure costbenefit of infection surveillance and control programs are varied, the report says that all available studies have benefited the hospital.

FROM: Centers for Disease Control and Prevention. Public health focus: surveillance, prevention, and control of nosocomial infections. M M WR 41:783-87;1992.

\section{Court Orders AIDS Patient to Pay Exposed Healthcare Worker}

In the first lawsuit of this type in the nation, the jurors in a Los Angeles Superior Court decided that a patient must pay $\$ 102,500$ for fraud and negligent infliction of emotional distress for concealing AIDS from a surgical technician who was exposed to her blood. The exposure occurred in 1991 when a plastic surgeon's scalpel inadvertently cut the technician's finger during a follow-up procedure for suture removal after a breast reduction. The technician was not wearing gloves during the procedure. The patient testified that she falsely stated on a medical form that she was not being treated for any illness or taking any medication, when in fact she was taking several medications for AIDS. She was diagnosed as HIVinfected in 1987.

The patient's defense centered on the failure of the breast center, where the procedure was performed, to enforce universal precautions, such as wearing of gloves. The court agreed with this and divided the blame for the injury- $60 \%$ to the patient, $26 \%$ to the plastic surgeon, and 13\% to the breast center. Although the patient's liability was only $60 \%$, she was liable for the entire award because she was also found guilty of fraud -- the first time that the law of fraud has been applied to the physician-patient relationship.

A number of patients have sued doctors and other healthcare practitioners for not disclosing they had AIDS, but this is the first case in which a healthcare worker is suing a patient. The concern is that this court decision may now shift the burden for healthcare workers' safety to patients.

AIDS activists charge that this is one more reason HIV-infected individuals will avoid seeking testing. Plans have been made to appeal the verdict (Boulais $v$ Lustig, BC038105).

\section{Federal TB Funding Increased for 1993}

American Lung Association President Lee Reichman announced that there had been a significant increase in federal funding for tuberculosis (TB) -- up from $\$ 40$ million to $\$ 105$ million this year. This increase is attributed, in part, to greater media attention to TB. Speaking at the second annual meeting of the National Coalition to Eliminate Tuberculosis, Reichman said that the $\$ 105$ million is still far below the $\$ 515$ million that is needed to fully implement the National Action Plan to Combat Multidrug-Resistant Tuberculosis. This plan, released by the CDC in 1992, calls for a series of activities to contain multidrugresistant $\mathrm{TB}$, including surveillance, laboratory diagnosis, patient management, screening, infection control, and information dissemination.

Some are concerned that state legislatures may misinterpret increased federal funding as a waiver of local funding. Experts warn that there must be a state infrastructure for TB control and additional funding will be needed.

\section{AHA Issues Revised AIDS/HIV Recommendations}

The American Hospital Association (AHA) has revised its recommendations for hospitals on AIDS and HIV infection to account for developments that have occurred since the initial policy was developed in 1988.

Topics highlighted in AIDS/HIV Infection: Recommendations for $\mathrm{H}$ ealthcare Practices and Public Policy include patient testing, managing HIV-infected healthcare workers, patient notification (lookback) programs, informed consent for HIV testing, preventing percutaneous injuries in healthcare workers, and the role of the public and private sector in financing AIDS care. Concerning patient testing, the AHA urges healthcare providers to incorporate patient risk assessment into standard procedures for taking medical histories and offering voluntary HIV testing to individuals at risk. In areas with a high HIV seroprevalence, some hospitals may wish to routinely offer HIV testing and encourage their patients to be voluntarily tested.

Regarding management of HIV and HBVinfected healthcare workers, the recommendations call for a case-by-case determination of fitness for duty within existing worker impairment programs. These recommendations do not advise that HIV-infected healthcare workers who have received clearance to practice from an expert panel disclose their HIV status to patients.

The AHA also advises against routine retrospective notification of patients who have been treated by an HIV-infected healthcare worker and advises a case-by-case evaluation to determine the likelihood of transmission.

To order the booklet, call the American Hospital Association, Order Processing, at 1-800-AHA-2626 (catalog no. 094691). 